\title{
Det var en gång en flicka som blev våldtagen...
}

\section{Tema och berättarteknik i Med Marias ögon och Ave Eva}

\author{
Ungdomsromanerna Med Marias ögon av Stefan Casta och Ave Eva av Sulaima Hind \\ handlar båda om sexuella övergrepp, skuld, hämnd och försoning. Wiveca Friman gör en \\ närläsning av berättartekniken $i$ de båda böckerna och ser hur författarna gestaltar olika \\ relationer och hur respektive huvudperson berörs av det trauma en våldtäkt innebär.
}

Två tematiskt aktuella och litteraturvetenskapligt intressanta böcker, Med Marias ögon ${ }^{1}$ och Ave Eva², som kom ut samtidigt i Sverige respektive Danmark är föremål för min läsning i denna artikel. I det ena fallet är författaren en man, Stefan Casta (f1949) och i det andra en kvinna, Sulaima Hind (f1969). De problematiserar båda olika relationer, det smärtfyllda i att bli vuxen och hur en ung kvinna bearbetar en starkt traumatisk händelse och anpassar sitt liv därefter. Vid en första anblick verkar de båda romanerna ha mycket gemensamt. Men efter en närläsning är det snarare olikheterna i såväl budskapet som den litterära framställningen som framträder tydligast. Artikeln utgår från originalutgåvan av Med Marias ögon medan citaten ur Ave Eva är hämtade från den danska originaltexten. ${ }^{3}$

Maria är 15 år när de avgörande händelserna utspelas och Eva är 16 år. Båda flickorna står inför ett vägskäl. Maria åker på konfirmationsläger. Eva börjar på en gymnasieutbildning. De utsätts för grova fysiska och sexuella övergrepp som även vållar dem psykisk skada. Maria får hjälp av en psykolog och Eva söker en samtalspartner i den man som varit faderns förläg- gare och de betraktar i samtalen med dessa det skedda i ett distanserat perspektiv. Mycket intressant är hur de närmar sig sin egen person. Maria ser sig som i en spegel och inleder under kapitelrubriken "Det var en gång en flicka" med orden: "Mitt namn var Maria, nu är det Airam" (s. 10). Eva gör observationer och ser tillbaka på den hon en gång var: "Jeg..., /---/ ... var engang en pige der hed Eva ...hun ...hun ... begyndte på noget ..." (s. 9).

Innehållet i en modern ungdomsroman ligger i gränslandet till vuxenromanen och det resulterar ofta i att den även formmässigt kräver mycket av den unge läsaren. Med Marias ögon startar i händelsernas centrum med en onumrerad inledning och sedan kommer en rubricerad men ej numrerad presentation av "Mannen med den röda katten", dvs. psykologen som Maria återger sin berättelse för. Det innebär återblickar som ger pusselbitar efter hand och håller läsaren i ovisshet fram till slutet. Ave Eva tar i första kapitlet, rubricerat 0 , avstamp i ett barndomsminne. Därefter förflyttar texten sig till den nedgångna kvinnan Eva som vaknar i sitt tillhåll intill järnvägen, beger sig in till staden och tar 
kontakt med förläggaren som hon delger sin historia.

Båda romanerna har således en ramberättelse som knyter samman innehållet och den inre strukturen i romanerna byggs upp genom olika kapitel där händelser och känslor lyfts fram allteftersom de gör sig påminda hos respektive huvudperson eller av att lyssnaren manar på.

\section{Det var en gång}

\section{en flicka som hette Maria}

Med Marias ögon inleds med en kort glimt av en flicka som halvnaken ligger "utspilld i blåbärsriset". Därefter rullas hennes historia upp. Som barn blir Maria genom en olyckshändelse synskadad. Men hon har en trygg familj och många vänner och lever ett ganska vanligt liv.

I romanen finns fyra olika medvetandenivåer. Den första är nuets berättartid i den reella världen och i denna möter Maria psykologen. Den andra är dåets nu i den reella världen som omfattar laddade glimtar från barndomen och minnen från konfirmationslägret, dvs. de händelser Maria försöker berätta för psykologen. Den tredje är en fantasivärld, vilken är en spegelvänd värld som Maria använder för att kunna distansera sig från det smärtsamma i sin berättelse. Denna värld beskrivs med områden som Rikkeyvulkanen och Singoskogen och ger ett arkaiskt intryck. Maria minns i korta, ibland smärtsamma, men ofta glädjefyllda återblickar och bearbetar sitt trauma. Jag vill påstå att innehållet i Med Marias ögon lyfts fram och blir extra angeläget just på grund av den form som denna ungdomsroman presenteras i. Maria vänder inledningsvis på vedertagna begrepp: "Mitt namn var Maria, nu är det Airam. Det är Maria bak och fram. Jag tycker att det är enklast att börja så. Att inte krångla till det. Och ändå visa att jag är en annan människa" (s. 10). I denna naturnära värld talar Airam till ett Du, en ljushårig ung man som i sin tur meddelar Airam sin kärlek. För att komma tillbaka till den reella världen och förstå den konstaterar hon att "[m]itt namn var Airam, nu är det Maria" (s. 47). Den fjärde nivån är drömvärlden som bearbetar svåra händelser och frågor, fungerar som mellanled och förbinder fantasivärlden med den reella världen.

I Med Marias ögon möter vi ett mysterium redan i inledningen. Vi vet inte vem som talar och ännu mindre vem som ser "[f]lickan [som] ligger utspilld i blåbärsriset" (s. 6). Så kommer en beskrivning av vad man kan uppfatta av denna flicka. Hon är vacker, har mörkt, lite rufsigt hår och har ett silverhjärta kring halsen. "Hon är femton år" (s. 6) får man veta. En exakt uppgift som bara den som känner henne kan ge? Men först har man fått veta att hon är nästan naken och att hennes röda tröja är uppdragen mot halsen och att en orange flytvästrem har snott sig runt flickans arm. Hon har blod i ansiktet.

\section{En midsommarnattsdröm och andra drömmar}

På sin hemsida skriver Casta: "Den här berättelsen börjar och slutar en midsommarafton. Eller, kanske har den inget slut? Jag önskar att läsaren efter sista sidan ska känna lust att läsa den första sidan igen." ${ }^{4}$

Casta använder Shakespeares En Midsommarnattsdröm som intertext och flätar in älvor, småtroll och nyfikna djur, drömmar och trolska scenerier i sin egen berättelse. När småtrollen ser Maria ligga där i blåbärsriset blir de upprörda och plockar undan trosor och jeans som ligger utspridda tillsammans med en ölflaska runt henne. Älvorna plockar sju vita skogsstjärnor och lägger under flickans huvud och "en häxas mörka ande flaxar bort över skogen och skriker klagande: - Maria! Maria!" (s. 7). 
Drömvärlden, här så tydligt relaterad till En Midsommarnattsdröm, bildar övergångar och ger förklaringar till de andra världarna. Maria ligger där stilla i gräset "som om hon [...] drömmer en saga som är vackrare än denna" (s. 7). ${ }^{5}$

I smärtfyllda situationer återkopplar Maria via drömmen till den reella världen från den främmande: "Jag tror att jag drömmer en dröm som handlar om att jag ligger och sover nånstans och drömmer en helt annan dröm. Rakt genom den drömmen kan jag följa dina rörelser i mörkret. /---/ Jag känner din tunga andhämtning när du sänker dig ner över mig. /---/ Känner en hård kropp pressas mot min egen" (s. 23). I fantasivärlden hämnas Airam direkt genom att bitas och hota med en machete och resultatet blir att "Du" faller mot en sten och svårt skadar huvudet. I detta läge känner hon att hon kunde ha dödat honom, dvs pojkvännen Carl som inte respekterar hennes gräns. Detta är nog det närmaste Maria kommer det övergrepp hon utsatts för i sin berättelse för psykologen.

\section{Marias ögon}

Det finns en mängd ledtrådar kring Marias ögon som pekar på att hon är synskadad men ingenstans står det uttalat och inte förrän man är uppmärksam på det förstår man hur detta påverkar hennes beroende av andra människor. I Marias fall rör händelserna i barndomen sig mera om en konstruktion i hennes eget sinne. När hon finner en gunga ute på konfirmationslägret kommer minnena till henne. Hon berättar om en olycka när hon som liten får en gunga mitt i ansiktet. Detta är förklaringen till en del av hennes beteende. Hon är i stort sett blind efter denna olycka.

Titeln Med Marias ögon som i och för sig är en paratext förleder mig först att tolka texten som Marias version av en händelse som hon ser det, medan det i själva verket innebär att just det hon inte ser blir betydelsefullt. På en fråga från psykologen svarar Maria: "Fantasi är väl det som ögonen inte kan se", vilket skulle innebära att det som Maria berättar är fantasi (s. 31). Psykologen menar att Maria har gått över gränsen mellan fantasi och verklighet och drömmar. Maria svarar att om man inte vågar gå över den kan man inte se hela bilden. "Du blandar verkligheten med fantasi" säger psykologen. "- Och med drömmar, säger Maria. Dom är ju också en del av verkligheten" (s. 31). Här ligger en nyckel till romanens form. Det är gränsöverskridandena som möjliggör Marias värld - att se med Marias ögon.

\section{Sökandet}

Dagen efter att Carl och Maria varit ute på sjön och Maria avvisat Carls närmanden saknar Carl sitt halsband. Maria hjälper honom söka på platsen där de hade sitt möte. Texten går över i ett allmänt sökande och Eriks (ledaren för konfirmationslägret) röst ekar i Marias öron: "Vad söker du, Maria?" (s. 145). Här problematiseras religiösa föreställningar och konfirmandernas olika inställning till sin tro. Maria söker även närhet till andra människor och relationen till bästa vännen Stella utvecklas i en kärleksscen. De spelar också upp en vigselscen i kyrkan där de avger löften till varandra. Stella jämför med jungfru Maria. Hon säger också att "Gud är kärleken" och "[a]tt ingen kärlek kan vara fel" (s. 155). Så småningom bleknar kärleken till Stella och svärmeriet blir en länk till deras fortsatta starka vänskap och samhörighetskänsla. Samtidigt förälskar Maria sig i danske Søren och Carl som blir svartsjuk jämför henne nu med Lilith som fresterskan i förbund med djävulen och mörkrets gudinna. 
Under medeltiden lyfte man fram Lilith som Adams första hustru och i mytologin och i folktron ansågs hon vara upphov till bl.a. demoner. Hon representerar den mörka sidan av kvinnligheten och sägs vara en stormdemon. Lilith förknippas också i konsten med ormen. ${ }^{6}$ När midsommarbålet är färdigt får Maria "en egendomlig känsla av att det är jag som sitter däruppe på bålet" (s. 205). ${ }^{7}$

Midsommarafton sätter sig Maria och dricker för mycket öl. Hon för ett animerat samtal med Lilith och förklarar varför det är så svårt med Carl och Søren och att hon bara gör fel saker hela tiden När bålet tänds och dockan, enligt den danska seden, börjar brinna känner hon att det skulle kunna vara hon själv och tänker: "Åh, Lilith. Älskade Lilith" (s. 217). Det innebär att när hon identifierar sig med Lilith tar hon också på sig en skuldbörda för det som händer men beklagar samtidigt att vara utsedd att vara den som störtar andra i fördärvet.

\section{Kärlek, våld}

Ur Bibeln, "Höga visan", kapitel VIII citeras fyra rader i inledningen till Med Marias ögon:

Bär mig som ett sigill vid ditt hjärta.

Som ett sigill vid din arm.

Stark som döden är kärleken,

Lidelsen obeveklig som graven. ${ }^{8}$

Dessa rader är hämtade ur vers 6 och det är bruden som talar. Sista raden i versen är dock utelämnad men lyder: "Dess pilar är flammande eld, en ljungande låga".

I en not till denna vers ges följande förklaring: "ett sigill vid ditt hjärta... vid din arm. Sigill kunde bäras på bröstet i en snodd runt halsen eller vara fäst vid en armring eller en fingerring". ${ }^{9}$ Höga visan utgör en komplicerad intertext till Med Marias ögon. Här kan anas en anknytning till Lilith och underliggande toner kopplade till brudmystiken och Marias kärlek till Stella.

Carl däremot kan inte behärska sin svartsjuka och sin längtan efter Maria och i sin frustration följer han efter och överfaller henne under midsommarnatten och gör henne illa både fysiskt och psykiskt. Rubriken "det är bara du tänker jag" andas Marias ointresse för Carl (s. 228). Att vara "bara du" i detta sammanhang är inte så smickrande.

Det är dock tveksamt om våldtäkten fullbordas. När Maria slutligen berättar händelsen är det för Stella hon berättar även om hon växelvis distanserar sig:

Du trycker dina läppar mot mina innan jag hinner reagera. Maria känner inte igen den kyssen. /---/ Så känner jag en iskall hand som trevar under min tröja. /Nej, tänker hon. Nej, det här blir alldeles fel. /---/ Jag känner hur din lem tar spjärn mot mitt underliv. /---/ Nej, försöker hon skrika. Du gör mig illa, försöker hon skrika. Sluta då, försöker hon skrika./---/ Din flytväst skaver mot mitt ansikte men det känner jag inte längre, bara hur du kämpar med ditt byxtrassel som hindrar dig från att bryta dig in i mig. /---/ Så hugger jag. Jag blir förvånad över att jag träffar. Jag känner hur sekatören slår i något och undrar om det kan vara ditt huvud för det är så hårt. /---/ Ditt skrik fyller ut mörkret omkring oss.

- Din jävla hora, skriker du (s. 229ff).

Berättelsen ligger mycket nära den ovan beskrivna episoden från fantasivärlden då hon försöker få psykologen att förstå vad som hänt och som förstärker den vanmakt hon känner.

\section{Skulden, hämnden och försoning}

Carl upprepar sitt förakt eller snarare hat mot henne. "Din jävla hora, snyftar du" tänker Maria tillbaka men snyftningen ger 
också en bild av honom som sårbar (s. 231). Maria minns och bearbetar. Maria bearbetar också skuldfrågan i sin dröm där hon som Airam blir ansvarig för att Duet [Carl] skadas svårt.

Jag tror att det var så här det började. / Men just då, den här natten, vet jag inte att det är slutet och inte början. Slutet för honom. Kanske för oss alla. /---/ Jag funderar på hur jag ska göra, på vilka alternativ jag har. Först tänker jag bara på att ge mig av. Sen förstår jag att det nog är omöjligt. Så börjar jag inse vad jag har gjort. Då kommer skuldkänslorna rasande som väldiga stenbumlingar. De lägger sig på mina axlar. / När jag går tillbaka är jag så nervös att benen skakar (s. 24f).

När hon ska återge det som hänt hos psykologen går hon fram till högen med "Alla Viktiga Papper Om Maria" och sprider dem i rummet. Sedan går hon tillbaka till sin stol och skriker: "Det var Marias fel!" (s. 221). Psykologen motsäger henne: "Nej Maria, du måste sluta anklaga dig själv. Du har ingen skuld i det som hände. Förstår du det?" (s. 222). Här finns en lucka som ger möjlighet till olika tolkningar. Vad var det Maria ansåg vara hennes fel? I en tolkning kan det betyda att hon med sin gräns fick Carl att tappa besinningen och att hon därmed var medskyldig. I en förlängning kan man tyda det som att det är hennes skuld att Carl drunknade. Det skulle innebära att hon identifierar sig med Lilith, stormdemonen, den som störtar andra i fördärvet.

Den inledning Casta vill att läsaren ska gå tillbaka till inrymmer även följande meningar: "När solen går upp och Guds öga upptäcker vad som skett rynkar Vår Herre sin panna. Dessa människor, tänker han. Dessa förtvivlade människor! Så suckar han så tungt att det börjar blåsa den här morgonen" (s. 7). Detta läser man redan i början av romanen och när man i slutet får veta att förövaren har förlorat sin flytväst och rapporteras saknad efter en båtolycka i hård sjö förstår man att det finns en tydlig förvarning till vad som ska ske. Hämnden läggs över på Gud. När han ser vad som hänt utmäter han straffet. Försoningstanken som är så framträdande i Castas författarskap i övrigt - finns den verkligen här?

\section{Inför framtiden}

Det är inte bara för psykologen eller Stella som Maria berättar, det är i högsta grad för sig själv. Genom denna samtalsterapi kommer hon till insikt om vad som egentligen hänt, får möjlighet att bearbeta det, återvända till vardagen och finner samtidigt den Maria som är hennes äkta jag.

Romanen har en epilog under rubrik "Ett år senare". Här finns ett uttryck för en försoningstanke. Epilogen inleds med orden: "Jag har ditt hjärta i halsgropen. /---/ Jag tänker på dig. På dig som jag älskade." (s. 234). Det syftar på silverhjärtat som Maria till sin femtonårsdag fick av Carl men för också tankarna till "Höga visan" och det sigill som omtalas där. Hon minns Erik som sa: "Du är en sån som söker efter något, Maria" och känner att det hon sökt är kärleken (s. 235). Den kärlek hon hyst för Carl kommer för alltid att finnas kvar även om det inför framtiden är kärleken till Søren som gäller.

\section{"Jeg..., ...var engang en pige der hed Eva ..."}

Ave Eva börjar med ett starkt laddat barndomsminne. Sedan får läsaren följa Evas start på ett alternativt gymnasium på Nørrebro. Där träffar hon ett glatt flickgäng; Siv, Rama, Nadia och Linse bland sina nya skolkamrater. Hon engagerar sig tillsammans med flickorna och är under slagorden "Pussy Power"10 med i olika raider mot porrbutiker. Hemma försämras förhållandet mellan 
föräldrarna som också försummar dottern. I skolan satsar hon på en uppsatstävling, men danskläraren Tom som lovat hjälpa henne begår i stället en grov våldtäkt när hon besöker honom i hans bostad. Chocken över denna händelse och föräldrarnas svek gör att hon isolerar sig från omvärlden och super ner sig, först i sällskap med pappan och sedan efter dennes död i ensamhet. Hon slutar som "baglady" eller "posedame" som det heter på danska.

Romanen inleds med kapitel 0 genom en scen med barnet och modern på utflykt: "Hon sad bag på cyklen. /---/ En solsort for op og baskede gennem Evas hoved" (s. 5). Koltrasten far vidare men benen finns kvar i munnen och hon försöker förgäves knäcka dem mellan tänderna. Nästa avsnitt i kapitel 0 handlar om Eva som den utslagna kvinnan. "Kvinden [som] vågner med en trykken for struben"(s. 5). Hon tar sig från uteliggarplatsen till innerstan där hon hejdar mannen som varit förläggare åt hennes pappa. Hon har en blå påse med pappersfragment $\mathrm{i}$ och följer med upp till hans kontor och drar "brummande" upp något ur sin påse som hon ger mannen. Det är några anteckningar att läsa från en "pølsebakken". ${ }^{11}$ "Er det tænkt som digte, eller måske små noveller?" frågar mannen. "Langsomt, som skal hver eneste stavelse findes i en overfyldt kælder og bæres op ovenpå, får hun det sagt: Ob...ser... va...ti...oner" (s. 8f). Kvinnan påminns via datorns summande om något hon haft $\mathrm{i}$ halsen för länge sedan och minns den flicka som legat på golvet med ett "motorlyd" i halsen, med känslan att hon skulle lyftas upp från kroppen som låg på golvet. Förläggaren tittar uppfordrande på henne och uppmuntrar henne att tala. "Jeg... var engang en pige der hed Eva... hun... hun... begyndte på noget..." (s. 9). Därefter berättar Eva sin historia för förläggaren.

\section{Männen}

Eva upplever en spirande romans med en ung man kallad Helse. Helse tar en av hennes rödblonda hårlockar och förser henne med en nyckelhållare i form av en ljusstav. Man skulle kunna tolka detta som ett kontrollbehov men i sitt sammanhang framtonar snarast känslan av ett förbund mellan dessa båda unga människor.

Hind tecknar annars en tämligen mörk bild av de män Eva möter. Överallt i samhället finns påflugna män som generar henne med plumpa antydningar, t.ex. pølsemanden som blinkande menar att "...du kan da tage en stor én ikk'?" (s. 87). Det kan i texten också tolkas som en förvarning om vad som väntar henne.

Eva som känner glädje över den uppmärksamhet hon får från Helse blir samtidigt påverkad av danskläraren Tom. Dels är han en auktoritet när det gäller skrivandet, dels är han manligt attraktiv. När Eva kommer i enrum med Tom kan hon inte värja sig utan blir totalt överrumplad först av hans ömhet och sedan av sömn från det Irish coffee som han lagat och som troligen varit spetsat med någon drog.

Søvndrukkent strakte hun sig ud, smeltede og gav efter for de stærke hænder der langsomt, men sikkert fik hende til at åbne sig. Skiftende drømmesekvenser blandedes med de blide berøringer som glødede mod hendes hud (s. 97).

I denna första sekvens kopplar Eva beröringarna till Helse men kommer till sans när han blir mera påträngande:

Da hun stivnede under ham, knugede han hende tættere ind til sig og bevægede sin krop endnu hurtigere og hårdere. /---/ Eva prøvede at få en lyd ud, /---/ Men kun en lille, skarp tone kom ud, og den knækkede da han lagde en flad hånd mod hendes strube of 
løftede sig op, så overkroppens vægt hvilede på halsen (s. 97).

Enda sättet att uthärda är att främmandegöra sig under den råa våldtäkten:

Eva var der ikke, der lå en krop under manden, og hun vidste præcis hvad der foregick i den, men den var ikke hendes. /---/ Hun lå alene på sengen mellem de krøllede roser med hånden mod struben og en våd fornemmelse af kødsår mellem de nøgne lår. /---/ så kom hun op, trak famlende i tøjet og løb (s. 98).

Helse är den ende som uppskattar henne för den hon verkligen är men hon försummar honom först för sitt engagemang i kvinnofrågorna. Sedan efter våldtäkten drar hon sig själv undan. När de vandrat över till kyrkogården ${ }^{12}$ och Helse börjar smeka henne blir hon påmind om Toms övergrepp och vill inte att han ska in dit där hon besudlats. Därför flyr hon. Hon går hem äter och dricker tillsammans med pappan och avskärmar sig från samtliga de unga människor hon nyss byggt upp en samhörighet med.

I den fortsatta texten blir handen ett ledmotiv och det blir den som styr. Eva återkommer ständigt till kvävningskänslan och så snart hon känner sig trängd gör handen sig påmind och rösten övergår i ett brummande ljud. Det som Hind beskriver är med andra ord hur en vuxen auktoritet har berövat Eva hennes oskuld, integritet och förmåga att kommunicera.

Samtidigt beskrivs naturalistiskt hur en kladdig vätska tillsammans med blodstrimmor rinner nedför hennes lår och hur hon som en påtaglig reaktion på våldtäkten får ett maniskt behov av att rena sig. Men den nedsmutsning hon utsatts för går inte att skrubba bort. Här finns en intressant parallell till faderns förfall. Han stillar sin ångest och sitt magsår med alkohol och
Eva torkar upp hans blodstrimmiga uppkastningar efter att ha blivit nedkladdad av dem på toaletten. Senare finner hon honom medvetslös med saliv och blod sipprande i mungipan och till sist ligger han död.

Den ende positive mansgestalten är paradoxalt nog fadern som bokstavligen super ihjäl sig medan klirret från isbitarna i whiskeyglaset ger henne en trygghet genom den närvaro det signalerar. Senare skall hon genom vaniljdoften från förläggarens pipa känna samma tillit och förtroende. $\AA$ andra sidan förknippas förläggaren när han berömmer henne med orden "Du har virkelig en god iagttagelsesevne, det er der ingen tvivl om" (s. 112) med danskläraren som i samband med en inlämningsuppgift konstaterat att "alene hendes iagttagelsesevne var guld værd" (s. 26). Med dessa associationer skulle förläggaren kunna representera såväl frestaren som tryggheten.

\section{Identitet och identifikation}

Det är endast titeln Ave Eva som använder uttrycket "Ave Eva" dvs det inverterade förnamnet men det sätter spår av distans in $\mathrm{i}$ läsningen. Titeln understryks av omslagsbilden som jag också vill betrakta som en paratext och som visar en ljus ansiktshalva och en mörk, delvis skymd bakom ett tillrufsat hår. Kontrasten visar två flickor i en och samma gestalt och ger samtidigt en spegeleffekt. Detta får betydelse för tolkningen av romangestalten Eva. Med tanke på betydelsen av ordet ave som "var hälsad" finns det i berättarledet också någon som förhåller sig personlig till Eva. ${ }^{13}$

Kierkegaards existensfilosofi som upptar faderns tankar och skrivande kommer till uttryck när han finkänsligt vill visa att han känner att något är galet med Eva och i förbigående yttrar: "Kierkegaard siger at mennesket skal ville sig selv, ellers lever 
det i fortvivelse, hvad enten det er sig det bevidst eller ej" (s. 105). Detta är en central mening för tolkningen av romanen. Kierkegaard lyfter i sina skrifter fram att människan måste förhålla sig till sin egen situation och att hon därigenom får möjlighet att ingripa och ändra på sitt eget liv. ${ }^{14}$

Tidigt försöker Eva lämna barndomen genom att städa ur sitt gula rum men nallen Adam behåller hon. Han blir i berättelsen den enda positiva länken till barndomen medan det gula rummet ter sig som skrämmande. Eva försöker också frigöra sig från modern och säger direkt när hon börjat på gymnasiet att "[j]eg har ligesom mit eget liv nu, mor" (s. 45). Namnet Evapige kan hon inte heller fördra längre. Modern beskrivs i stort som likgiltig inför dottern och sätter sig själv i första rummet. När modern lämnat dem för en annan man försöker Eva via mammans kläder identifiera sig med henne. Mycket intressant är att Hind endast låter detta resultera i skoskav, dvs mamman skaver på fötterna likt fågeln en gång skavde i munnen och förstärker det struptag hon hela tiden bär med sig och som ger henne en ständig ångest.

Vid övergreppen blir Toms dotter vittne till händelserna. Eva låser in henne men minnet av den lilla flickan förföljer henne. Under sin berättelse kommer Eva ofta tillbaka till sin barndom med hemska minnen från epilepsianfall som man bortförklarade med att hon var argsint. Hur ska hon då kunna frigöra sig från barnet? Hennes egen barndom flyter samman med nuet och genom hallucinationer och $i$ ångest ser hon barnet framför sig. "Havde hun ikke én gang for alle låst det inde, hvem i helvede havde lukket det ud?" frågar hon sig (s. 159). Hon flyr från lägenheten med några vinflaskor och har definitivt lämnat barndomen bakom sig.

\section{Hämnden och skulden}

Efter våldtäkten super Eva sig full och när hon träffar väninnorna under "grædepilen" på kyrkogården talar de om skuldfrågan och hämnd. Att de samlas just under tårpilen ger väninnorna närmast funktionen som gråterskor. Själv blandar Eva ihop pappans skämt om hennes likhet med "den skumfødte Venus" (s. 32), sin egen presentation för Helse som "Eva, som den første og mest skyldige kvinde i verden" (s. 47) och Helses tilltal "Hej, Eva, din skyldige skønjomfru" (s. 77). "Jeg er mig, zhden skummeltskylzhdige skønjomfru, jeg er,..." sluddrar hon och fortsätter "Jeg gik jo selv zhderop..." (s. 108f). Rama som är den starkaste av väninnorna övertalar henne: "Men for helvede, Eve, føler du dig måske ikke voldtaget?" /--/ "Så ER det voldtægt, Eva, det er VOLDTÆGT!" (s. 109).

Våld föder våld. Gemensamt arrangerar de fem flickorna en våldtäkt på Tom som sövs ned. En penisattrapp spänns fast på hans hustru och Eva flyr när hon ser "Ramas muskuløse arme der bare blev ved og ved og ved med at dunke kvinden ind mod manden, og skjult bag det hvide kød attrappen, den glinsende, sorte stav der smadrede dem, der fik det fine til at briste" (s. 117) samtidigt som den lilla dottern kommer ut från sitt rum.

Efter faderns död går Eva in i rollen som baglady. Hon samlar tomflaskor som hon omsätter till billigt rödvin och finner ett tillhåll i en nisch intill järnvägen. Så vaknar hon med en uteliggare över sig. Han vill stjäla det hon redan förlorat och hon översköljs av minnet från Toms övergrepp. Hon får kraft genom det hon tidigare stridit för, skriker PUSSY POWER och trycker och vrider om en avslagen flaska mot hans hals med motivering att han var ännu mindre värd än hon. Symboliskt sett har hon nu 
hämnats ännu en gång. Det blir ett bevis på att det flickorna gemensamt stred för i sitt feministiska engagemang gäller kvinnans roll i förhållande till mannen i den värld där hon hamnat.

Vid rättegången får hon ett anfall och avskärmar sig: "Det var slet ikke hendes krop, det havde alt sammen intet som helst med hende at gøre. Hun skulle bare bære den, det var alt" - ett yttrande som får som funktion att även texten lyfter sig från den enskilda episoden och blir allmängiltig (s. 173).

\section{Framtiden}

Eva går ytligt sett under men hopp finns ändå om ett nytt liv med utgivning av hennes observationer. Skrivandet som först entusiasmerat henne och sedan varit orsak till att hennes liv förstörts blir till slut genom de små anteckningslapparna det som befriar henne. När romanen slutar går berättelsen tillbaka till förläggarens rum. Hon reser sig och de ler mot varandra. - "Vi ses ... Eva," säger han och hon svarar fnissande "Den skummeltskyldige frøken Andersen" (s. 174). Hind har för mig bekräftat att ordet "skummeltskyldig", som under min läsning förbryllat mig, är ett "hjemmegjort ord". ${ }^{15}$ Helt klart bygger det på betydelserna mörker och skuld, kanske det som föregår i skydd av mörkret. Första gången det nämns är när Eva i berusat tillstånd kallar sig själv "zhden skummeltskylzhdige skønjomfru". Jag tolkar slutet som att Eva fått distans till sig själv, att hon i Kierkegaardsk anda har förstått betydelsen av att "mennesket skal ville sig selv, ellers lever det i fortvivelse".

En alternativ tolkning av det som sedan händer är att förläggaren ger ut den roman som får titeln Ave Eva. Ett motiv för en sådan tolkning är att Eva som i ramberättelsen helt naturligt kallar sig "jeg" i berättandet använder egennamnet Eva eller "kvinden" om sig själv och på så sätt betraktar händelserna i tredje person.

\section{Två romaner - två författare}

Två ungdomsromaner, starka var för sig, ger tillsammans en bild av att den som kränks genom övervåld behöver tid för bearbetning. Ett barn tar lätt skulden på sig och för att barnet inte helt ska utplåna sig behövs en vuxen att förlita sig på för att det skall finnas hopp om en framtid. Casta och Hind erbjuder och kräver mycket. Med författarens självklara rätt blir gränserna ibland suddiga och luckor i texten uppstår. Associationerna får spelrum och läsaren får tillfälle att läsa in egna erfarenheter, förväntningar och slutsatser. Castas språk är varsamt, vackert, kvardröjande i detaljer och stämningar, främst i de olika relationer Maria har till såväl den reella världen som fantasivärlden. Någonstans finns också försoningen. Hinds synvinkel och språk är liksom huvudpersonens observerande. Det är utanförskapet som lyfts fram i kontrast till den samhörighet som finns korta stunder i Evas liv. I Marias barndom finns trots en svår olycka ändå en trygghet. I Evas barndom finns det hotfulla, skrämmande och rädslan att bli övergiven.

Att dessa båda ungdomsromaner trots sina stora olikheter ändå känns så nära förknippade med varandra vill jag hänföra till berättarformen men i ännu högre grad till att de behandlar teman som är aktuella i alla tider och får stor betydelse för unga människors steg in i vuxenlivet - det handlar om processen att bli vuxen.

Var går gränserna när det gäller våldtäkt och vilka blir konsekvenserna? Det är i grunden dessa frågor Med Marias ögon och Ave Eva handlar om. Jag tror inte att kulturskillnader mellan Sverige och Danmark, en generationsfråga eller det faktum att det är 
en manlig respektive kvinnlig författare som skriver, är det avgörande i de olika sätten att behandla samma tema, utan att det

\section{Noter}

${ }^{1}$ Stefan Casta, Med Marias ögon, Stockholm: Opal, 2003

2 Sulaima Hind, Ave Eva, København: Høst \& Søn, 2003

${ }^{3}$ Vid denna artikels tillkomst finns ännu ingen svensk översättning tillgänglig och min uppfattning är att citaten ur originalet bättre speglar det jag vill lyfta fram än om jag själv skulle göra en översättning.

${ }^{4}$ www.stefancasta.se

${ }^{5}$ Jag har i min läsning låtit mig inspireras av Shakespeares drama och också Cecilia Sidenbladhs och Tord Nygrens version i bilderboksformat för barn som utgavs samma år som Med Marias ögon. Med mig får jag då bilden och doften av alla växter som ofta kryddar Castas texter. William Shakespeare, En midsommarnattsdröm, Stockholm: Ordfront, 1983, Cecilia Sidenbladh \& Tord Nygren, En midsommarnattsdröm, Stockholm: Rabén \& Sjögren, 2003.

${ }^{6}$ För en översikt se t.ex. http://en.wikipedia. org/wiki/Lilith.

Se även Nationalencyklopedin, band 12, där det omtalas en amulett som skulle skydda kvinnor och barn från Liliths ondska. Där nämns även att i modern feministisk ideologi "formas en positiv symbolgestalt för det rättfärdiga kvinnoupproret". helt enkelt beror på att det är två olika människor med olika erfarenheter och olika ambitioner i sitt författarskap.

7 I Danmark firar man vid midsommar St Hans med eldar längs kusten (efter Johannes döparen som dog martyrdöden). Traditionen med en häxdocka som placeras på bålet härrör sig från 1920-talet för att påminna om häxbränningarna under 1500- och 1600-talen. Se t.ex. http://en.wikipedia.org/wiki/Midsummer.

${ }^{8}$ Bibeln. Bibel 2000 med noter, parallellhänvisningar och tillägg. Örebro: Marcus, 2001, s 790.

${ }^{9}$ Ibid.

10 "Pussy Power" - en feministisk kampsång som protesterar mot exploatering av kvinnan som sexsymbol.

${ }^{11}$ En bit kartong som används som underlag vid servering av varm korv med tillbehör.

12 På Nørrebro ligger Assistanskyrkogården som även används som park och där bland annat Kirkegaard ligger begravd. Man kan av kontexten dra slutsatsen att det är dit ungdomarna beger sig för att koppla av eller diskutera livsfrågor.

${ }^{13}$ På sin hemsida berättar Hind att hon själv levt som gatubarn och att hennes erfarenheter därifrån ligger till grund för hennes skrivande. www.sulaimahind.dk

${ }^{14}$ Se t.ex. Filosofilexikonet, red. Poul Lübcke, Stockholm: Forum, 1988.

15 E-post 2006-05-26 